\title{
Lessons of Bioethics in Legal Education to Face the Challenges of COVID-19 in the Protection of Individuals and Groups of Special Vulnerability: An Approach from a Latin American Perspective
} Tovar $Y^{*}$
Professor of Philosophy of Law, Law Faculty, National Autonomous University of Mexico,
Mexico

*Corresponding author: Yvonne Tovar, Professor of Philosophy of Law, Law Faculty, National Autonomous University of Mexico, Mexico; Email: ygtovars@derecho.unam.mx

\section{Opinion}

Volume 3 Issue 4

Received Date: October 16, 2020

Published Date: October 22, 2020

DOI: $10.23880 /$ abca-16000143

\section{Abstract}

The Covid-19 pandemic has unveiled some of the problems that mankind still ought to face, such as the need of strengthening the physical, mental and social health protection of individuals and groups of special vulnerability. The delicate situation that some countries in Latin America are experiencing due to the pandemic outbreak indicates the convenience to explore the importance of Bioethics in Legal Education in order to protect human dignity and human rights, assess the actions of the public, private and social sector, as well as offer new insights on legal research. For that matter, the Universal Declaration on Bioethics and Human Rights is a significant starting point in order to acknowledge the principles that ought to be taken into account in order to deal with the problems arisen from Covid-19, as well as with the future challenges of the human kind.

Keywords: Bioethics; Legal Education; Individuals and Groups of Special Vulnerability; covid-19

\section{Introduction}

The study of Bioethics in Legal Education is significant to face the challenges of Covid-19. Certainly, the approach to the ethical implications and applications of medicine, life sciences and technology in humans from a multidisciplinary perspective may assess the appropriate decisions in order to protect human rights, specially of those individuals and groups of special vulnerability that have been severely suffered the consequences of the pandemic.

In the context of the problematic that some of the Latin American countries are currently facing in dealing with Covid-19, which has even worsen the health system and deepened the difficulties to grant the right to health, Bioethics may offer interesting reflections and research in order to protect human dignity and human rights from the consequences of the pandemic threat. In that regard, the Universal Declaration on Bioethics and Human Rights, adopted by acclamation on October 19, 2005 by the $33^{\text {rd }}$ session of the General Conference of United Nations Educational, Scientific and Cultural Organization, is a starting point for Law students to approach to the principles that must be respected by individuals and States. This approach urges a further transformation of legal education in order to explore new insights on the principles, problematic and proposals on the current and future issues that concern human kind.

\section{Towards the Transformation of Legal Education in the Amid the Covid-19 Pandemic}

Covid-19 has brought disruptions and uncertainty to the society that poses several questions that, among others, aim 
at determining if the State is fulfilling its function of effectively granting human rights, specially the right to health in its physical, mental and social dimension. It is expected that new proposals, discussions, insights and solutions should arise in order to understand and solve those problems caused by Covid-19.

One of the spheres that is desirable to offer alternate approaches to the Covid-19 pandemic is in Legal Education, in which students and professors should develop critical legal research, debates and analysis to question those decisions taken by States and the International Community that directly or indirectly have led to more than $39,170,503$ coronavirus cases and 1,102,844 deaths worldwide and the implications that this situation may represent to human rights and the rule of Law [1]. Critical legal researches and discussions play a notable role in identifying the mistakes of States, international community, private corporations and even society, as well as in assessing plausible solutions for this pandemic, from a legal perspective.

Since new problems require different methodological approaches, the Legal Education should consider deepening the study of Bioethics to better understand the scope of the decision making from multidisciplinary and interdisciplinary approaches to understand what is at stake in topics such as the protection of human rights, specifically of individuals and groups of special vulnerability, as well as the need to take appropriate decisions in the field of health to best respond the needs of the $21^{\text {st }}$ Century. Even though some Law Schools are gradually offering undergraduate and postgraduate courses on Bioethics, still it is needed to foster more studies, lectures and legal research on Bioethics, in order to prevent future hazards that the human kind may face.

\section{Contributions of the Principles of the Universal Declaration on Bioethics and Human Rights in the Decision-Making Process}

An starting point for deepening into Bioethics in Legal Education is the understanding of the Universal Declaration on Bioethics and Human Rights, whose principles are suitable to guide not only the actions of States, but also those of individuals and corporations in the protection of individuals and groups of special vulnerability. Certainly, the referred Declaration offers an interesting perspective of the intersection with human rights in the field of medicine, sciences of life and technology associated with human beings that may be helpful to face the challenges that arise to from Covid-19 and prevent discrimination [2], misunderstandings and indifference from influencing decision-making.
From its Preamble the UNESCO stresses the need to reinforce international cooperation in the field of bioethics, taking into account, in particular, the special needs of vulnerable population, Specifically, article 8 of the Declaration establishes the principle of the respect for human vulnerability and personal integrity, in the sense that in applying and advancing scientific knowledge, medical practice and associated technologies, human vulnerability should be taken into account. Individuals and groups of special vulnerability should be protected and the personal integrity of such individuals respected.

Moreover a systematic interpretation of the Universal Declaration on Bioethics and Human Rights may add further principles to guide the actions of individuals, groups, communities, institutions and corporations, public and private, promote respect for human dignity, protect human rights, and to foster multidisciplinary and pluralistic dialogue. For instance, principles such as non-discrimination and non-stigmatization, solidarity and cooperation, or social responsibility and health may be of special importance to reconsider the actions, decisions and attitudes adopted by mankind in order to protect individuals and groups of special vulnerability and even find new solutions to the Covid-19 pandemic. Legal education should therefore discuss and analyze how these principles should guide the decisionmaking in the Legislative, Judicial and Executive Branch that may aid to effectively face the challenges of the Covid-19 pandemic.

Within the Latin American region, in which Brazil and Mexico rank among the five most affected countries of the Covid-19 pandemic, the Legal Education should not continue going on with the traditional teaching methods and topics. On the contrary, further critical perspectives, multidisciplinary approaches, social awareness, as well as a serious compromise with the rule of Law and Human Rights need to be prioritized in order to demand accountability for those State and individual actions that are threatening the human rights. Also sensibility and social responsibility in the protection of the right to health is a relevant issue to reconsider, especially of those individuals and groups of special vulnerability, such as the elderly, who even before the pandemics were facing several troubles due to exclusion, discrimination and indifferent attitudes. For that matter, Bioethics offers an interesting approach to dimension the importance of human beings that should be considered in assessing and evaluating the actions of individuals and the State [3].

\section{Conclusion}

Almost 15 years after the adoption of the Universal Declaration on Bioethics and Human Rights, its principles 


\section{Annals of Bioethics \& Clinical Applications}

still have important lessons to offer to humanity in the protection of individuals and groups of special vulnerability, particularly on those Latin American countries that are suffering the consequences of the Covid-19 pandemic. Far from the discrimination, attacks, marginalization and indifferent attitudes of most of the society towards those individuals and groups, Bioethics in Legal Education offers an interesting insight to assess the decision-making process in order to grant the effective protection of human rights amid the Covid-19 pandemic and even to foster new legal research that may help to face present and future challenges of the human being.

\section{References}

1. De Albuquerque ASO (2011) The intersection between bioethics and human rights in the light of the Universal Declaration on Bioethics and Human Rights. Rev Derecho Genoma Hum 34: 21-50.

2. (2005) Universal Declaration on Bioethics and Human Rights. Legal Instruments.

3. (2020) Covid-19 Coronavirus Pandemic. Worldmeter.

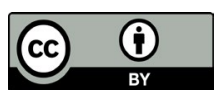

